\title{
The Effect of Intradiscal Platelet-Rich Plasma Injection for Management of Discogenic Lower Back Pain: A Meta-Analysis
}

This article was published in the following Dove Press journal:

Journal of Pain Research

\section{Min Cheol Chang' \\ Donghwi Park (D) ${ }^{2}$}

'Department of Rehabilitation Medicine, College of Medicine, Yeungnam

University, Daegu, Republic of Korea;

${ }^{2}$ Department of Physical Medicine and

Rehabilitation, Ulsan University Hospital,

University of Ulsan College of Medicine,

Ulsan, Republic of Korea
Correspondence: Donghwi Park Department of Physical Medicine and Rehabilitation, Ulsan University Hospital, University of Ulsan College of Medicine, 877, Bangeojinsunghwndo-Ro, Dong-Gu, Ulsan, 44033, Republic of Korea

Tel +82-52-250-7222

Fax +82-52-250-7228

Email bdome@hanmail.net
Objective: Although several researches of animal and human subjects have yielded promising results regarding intradiscal injection of platelet-rich plasma (PRP) for the management of intervertebral disc (IVD) pathologies, small sample sizes and unstandardized graft preparation procedures hampered these research efforts. Therefore, we conducted a metaanalysis to evaluate the effectiveness of intradiscal PRP injection for the treatment of discogenic lower back pain.

Methods: The PubMed, SCOPUS, Embase, and Cochrane Library databases were systematically searched for relevant studies published from January 01, 1980 to December 14, 2020. The keywords used for the search were (platelet-rich plasma) AND (intradiscal OR back pain OR lumbar spine OR discogenic). Filters were used to select studies with human participants; all study designs were included.

Results: After the systematic review, three articles, including one randomized control trial and two prospective observational studies, were included in the final analysis. Analysis of changes in visual analogue scale (VAS) scores showed that VAS scores were significantly reduced two and six months after intradiscal PRP injection (two months: standardized mean difference $[\mathrm{SMD}]=-0.837,95 \% \mathrm{CI}=-1.158$ to $-0.516, \mathrm{P}<0.001$; six months: $\mathrm{SMD}=$ $-1.430,95 \% \mathrm{CI}=-2.209$ to $-0.652, \mathrm{P}<0.001)$, but not after one month (SMD $=-0.661$, $95 \% \mathrm{CI}=-1.346$ to $0.023, \mathrm{P}=0.058)$. Regarding changes in Owestry Disability Index (ODI), ODI scores were significantly reduced after six months (SMD $=-0.964,95 \% \mathrm{CI}=$ -1.885 to $-0.043, \mathrm{P}=0.040)$.

Conclusion: Intradiscal PRP injections are effective in relieving pain and improving disabilities caused by discogenic lower back pain. However, the pain-reducing effect significantly manifests two or six months after the injections, but not after one month.

Keywords: platelet-rich plasma, discogenic lower back pain, degenerative disc disease, intervertebral disc, review

\section{Introduction}

Lower back pain is one of the most common causes of pain among the general population and can lead to varying disabilities and high socioeconomic burden. ${ }^{1,2}$ Most cases of lower back pain are self-limited; however, nearly $20 \%$ of patients with lower back pain recur within six months of the initial development and some patients then experience chronic symptoms. Although several spine structures have been known as generators of the pain, intervertebral disc (IVD) pathologies are responsible for nearly $40 \%$ of chronic low back pain cases. ${ }^{3}$ 
The IVD is the biggest avascular structure in the both of the human. ${ }^{4}$ Its limited vasculature is comprised of the metaphyseal arteries branches near the outer annulus. ${ }^{4}$ Thus, IVD relies on nutrients by passive diffusion from the surrounding end plate vessels. ${ }^{5}$ Therefore, an IVD has been known to have a poor healing ability due to its limitation of vascular supply and nutrition access. ${ }^{5}$ In the natural healing process of annular tears in an IVD, granulated tissue may form and abnormal nerve fibers might grow in the nucleus pulposus and annulus fibrosus. These changes cause discogenic pain by inflammation. In addition, this repetitive damage and healing process can lead to degenerative disc disease. These degenerative changes in the IVD result in cellular and morphologic changes, causing collagen fibers loss, proteoglycans, fibrocartilage, and increased enzymatic activity.

Various treatment options including physical therapy, ${ }^{6}$ medication, ${ }^{7}$ injection of epidural steroids, ${ }^{8}, 9$ and radiofrequency ablation, ${ }^{10}$ have been reported to manage the pain caused by IVD pathologies; however, these treatments cannot regenerate the structure of the disc. Moreover, a lot of patients have an insufficient response to these conservative treatments and their cases may even progress further to require surgical treatment such as lumbar fusion or disc replacement. ${ }^{11}$ However, these surgical treatment options have variable response rates and may cause serious complications. ${ }^{11}$

In recent years, platelet-rich plasma (PRP) has been increasingly used for the treatment of patients with musculoskeletal pain. PRP is a mixture of fibrin and growth factor achieved from autologous peripheral blood. ${ }^{4}$ PRP is prepared by centrifuging autologous blood to obtain a concentrated platelet solution. ${ }^{4,12}$ Many previous studies of animal models and human subjects have demonstrated the efficacy of PRP for the treatment of diseases that require repair of damaged or degenerated collagen-based tissues, such as ligaments, cartilage, and tendons. ${ }^{13,14}$

Given that an IVD is an avascular tissues with minimal regenerative ability, there has been increased interest in the use of PRP injections for the discogenic lower back pain management. The growth factors released by platelets include transforming growth factor (TGF) $\beta-1$, vascular endothelial growth factor (VEGF), platelet-derived growth factor (PDGF), and epidermal growth factor (EGF); therefore, PRP injection in an IVD may result in cellular and tissue proliferation. ${ }^{15-18}$ Although researches of several animal $^{19-22}$ and human subjects ${ }^{1,2,4}$ have yielded promising results regarding the use of intradiscal injection of PRP for the management of IVD pathologies, small sample sizes and unstandardized graft preparation procedures have hampered these research efforts. Therefore, to evaluate the effectiveness of intra-discal PRP injection for the management of discogenic lower back pain, we performed a meta-analysis of all available and relevant clinical studies of intradiscal PRP injection for the treatment of patients with discogenic lower back pain.

\section{Methods}

\section{Search Strategy}

This meta-analysis was conducted per the guidelines of Preferred Reporting Items for Systematic Review and Meta-Analysis. The PubMed, SCOPUS, Embase, and Cochrane Library databases were systematically searched for relevant studies published from January 01, 1980 to December 14, 2020. The keywords used for the search were (platelet-rich plasma) AND (intradiscal OR back pain OR lumbar spine OR discogenic). Select studies with human participants were selected by using filter. We included all design of the study; but, we only included articles published in English.

\section{Eligibility Criteria}

Articles were included in the present study based on the following criteria: 1) patients were treated for the alleviation of discogenic lower back pain; 2) intradiscal PRP injection was performed; and 3) visual analogue scale (VAS) or numeric rating scale (NRS) was used for evaluating the degree of pain. Review articles, case reports or letters, and studies that reported insufficient data/results were excluded from the meta-analysis.

\section{Study Selection and Data Extraction}

After the elimination of duplicate publications, two independent reviewers (MCC and DP) evaluated potential eligible studies to be included in the meta-analysis. Articles were screened for eligibility based on a review of their titles and abstracts; disagreements were resolved by consensus. After the primary screening, the two reviewers (MCC and DP) independently scrutinized the full texts of the eligible articles. Subsequently, data including the name of the first author, year of publication, sample size, demographic data, protocol for PRP injection, outcome measures [VAS and Oswestry Disability Index (ODI) scores], and major adverse events were independently extracted from each eligible article. 


\section{Quality Assessment}

The methodological qualities of the studies included in the present meta-analysis were evaluated using two different tools. To determine adequate sequence generation, blinding, incomplete outcome data, allocation concealment, selective outcome reporting, and other potential sources of bias in the randomized control trials (RCTs), the Cochrane Collaboration's Handbook were used. Judgments of bias were expressed as "low risk", "high risk", or "unclear risk." "3 Meanwhile, the NewcastleOttawa scale (NOS) was used to assess the quality of the prospective observational studies in three aspects of selection: selection of subjects, assessment of outcome, and comparability of groups. ${ }^{24}$ The quality of included study was graded as low (0-3), moderate (4-6), or high (7-9). ${ }^{24}$ By consensus, all divergences were resolved.

\section{Statistical Analysis}

Using the Comprehensive Meta-analysis Version 2 (Biostat Inc.), the extracted data were analyzed statistically. For each analysis, a heterogeneity test was conducted using the $\mathrm{I}^{2}$ statistic, which can evaluate the inconsistency extent among results. If $\mathrm{I}^{2}$ values were $>50 \%$, the data were considered to have substantial heterogeneity and the random-effects model was then used for data analysis. In contrast, if $\mathrm{I}^{2}$ values were $\leq 50 \%$, the pooled data were considered homogenous and the fixed effects model was applied for data analysis. Because the VAS and ODI scores are continuous variables, we evaluated the standardized mean differences (SMD) in changes from baseline and 95\% confidence intervals (CI). Subgroup analyses were conducted per the evaluation time points. $\mathrm{P}<0.05$ was considered statistically significant. For studies in which pain was reported using the NRS, the values were converted into VAS score equivalents.

\section{Results Study Selection}

A total of 1598 potentially relevant studies were selected in the preliminary search of all the databases (Figure 1). We excluded 133 duplicate studies and excluded an additional 1313 publications after their titles and abstracts were reviewed. The remaining studies were assessed through a review of the full texts of their articles. After the systematic review, three articles, which included one RCT and two prospective observational studies, were included in the final analysis (Table 1). The data of patients who received PRP injection in the RCT, which was conducted by TuakliWosornu et al, were extracted. ${ }^{4}$

\section{Study Characteristics}

The selected researches included 71 cases. The follow-up duration after PRP injection ranged from two months to six months. The characteristics of the included researches are presented in Table 1.

\section{Risk of Bias}

The study by Tuakli-Wosornu et $\mathrm{al}^{4}$ was an RCT and the risk of bias was evaluated based on the domains of the Cochrane Handbook 5.1 Assessment Tool. The RCT had low risks of bias in allocation concealment, random sequence generation, blinding of participants and personnel, and blinding of the outcome assessment, selective reporting, incomplete outcome data, and in other domains. The two prospective observational studies ${ }^{1,2}$ were assessed using NOS; both studies were rated 8 stars, which indicates a low risk of bias (selection of subjects: three stars; comparability of groups: two stars; outcome assessment: three stars).

\section{Meta-Analysis Results}

Regarding the changes in VAS scores after PRP injection, we analyzed the data recorded one month, two months, and six months after the treatment; the $\mathrm{I}^{2}$ values were $78.3 \%, 35.7 \%$, and $65.5 \%$, respectively. Therefore, the random-effects model was adopted for the analysis of the one-month and six-month outcomes (one month: $\mathrm{P}=$ 0.032, $\mathrm{Tau}^{2}=0.192, \mathrm{df}=1$; six months: $\mathrm{P}=0.089$, $\mathrm{Tau}^{2}$ $=0.208, \mathrm{df}=1)$, whereas the fixed-effects model was used to analyze the two-month outcomes $\left(P=0.212, \mathrm{Tau}^{2}=\right.$ $0.032, \mathrm{df}=1$ )

Regarding ODI scores, the ODI scores recorded six months after the PRP injection were used; the $\mathrm{I}^{2}$ values were $81.6 \%$. Hence, for analyzing the six-month ODI data, the random-effects model was applied $\left(\mathrm{P}<0.001, \mathrm{Tau}^{2}=\right.$ 0.361 , df $=1$ ).

Analysis of the changes in VAS scores showed that the reduction of VAS scores after one month was not significant $(\mathrm{SMD}=-0.661,95 \% \mathrm{CI}=-1.346$ to $0.023, \mathrm{P}=$ 0.058) (Figure 2). However, VAS scores significantly reduced two and six months after intradiscal PRP injection (two months: SMD $=-0.837,95 \% \mathrm{CI}=-1.158$ to -0.516 , $\mathrm{P}<0.001$; six months: $\mathrm{SMD}=-1.430,95 \% \mathrm{CI}=-2.209$ to $-0.652, \mathrm{P}<0.001)$. 


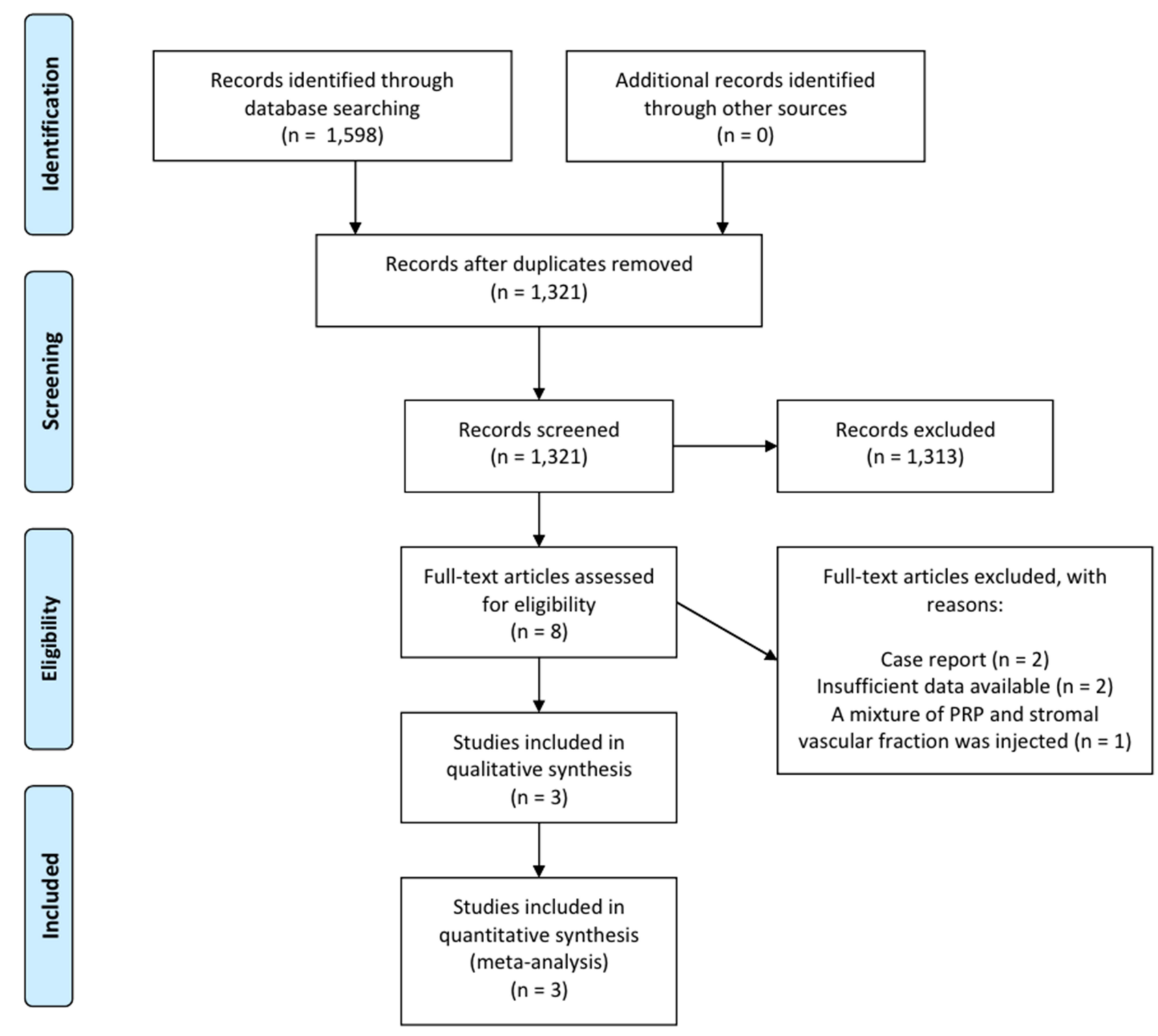

Figure I Flow chart showing the search results of the meta-analysis. Abbreviation: PRP, platelet-rich plasma.

Analysis of the changes in ODI scores revealed that ODI scores were significantly reduced six months after intradiscal PRP injection (SMD $=-0.964,95 \% \mathrm{CI}=$ -1.885 to $-0.043, \mathrm{P}=0.040$ ) (Figure 3 ).

No adverse events were reported in all three included studies.

\section{Publication Bias}

In each analysis, the data of two studies were used. Therefore, funnel plot analyses and quantification of the publication bias were not conducted.

\section{Discussion}

In the present study, we evaluated the effectiveness of intradiscal PRP injections for the treatment of patients with discogenic lower back pain. To the best of our knowledge, this study is the first meta-analysis to analyze the effect of intradiscal PRP injection on pain reduction in patients with discogenic lower back pain.

We evaluated all data in each included study and the results showed that lower back pain and disability caused by lower back pain were significantly improved two months and six months after intradiscal PRP injections, 
Table I Characteristics of the Included Studies

\begin{tabular}{|l|c|c|c|c|c|}
\hline $\begin{array}{l}\text { Publication } \\
\text { Year }\end{array}$ & Design & $\begin{array}{c}\text { Included Patients } \\
\text { (n) }\end{array}$ & $\begin{array}{c}\text { Disease } \\
\text { Duration, } \\
\text { Months }\end{array}$ & PRP Protocol & $\begin{array}{c}\text { Outcome Assessment } \\
\text { Time }\end{array}$ \\
\hline $\begin{array}{l}\text { Levi et al, } \\
2016\end{array}$ & $\begin{array}{c}\text { Prospective } \\
\text { observational } \\
\text { study }\end{array}$ & 22 & $\begin{array}{c}90 \text { (median) } \\
26-120 \text { (IQR) }\end{array}$ & $\begin{array}{c}\text { Spin for } 14 \text { minutes, 0.5-I.5mL per } \\
\text { disc }\end{array}$ & $\begin{array}{c}\text { Pre-treatment, I, 2, and 6 } \\
\text { months after treatment }\end{array}$ \\
\hline $\begin{array}{l}\text { Tuakli- } \\
\text { et al, }{ }^{4} 2016\end{array}$ & $\begin{array}{c}\text { Randomized } \\
\text { controlled trial }\end{array}$ & $\begin{array}{c}\text { Treatment group: } \\
\text { control group } \\
(29: 18)\end{array}$ & All patients $\geq 6$ & I-2mL per disc & $\begin{array}{c}\text { Pre-treatment, I week, I } \\
\text { and } 2 \text { months after } \\
\text { treatment }\end{array}$ \\
\hline $\begin{array}{l}\text { Jain et al, }{ }^{1} \\
2020\end{array}$ & $\begin{array}{c}\text { Prospective } \\
\text { observational } \\
\text { study }\end{array}$ & 20 & All patients $>$ & 2000 RPM for I2 minutes + 2400 & $\begin{array}{c}\text { Pre-treatment, } 3 \text { and } 6 \\
\text { months after treatment }\end{array}$ \\
\hline
\end{tabular}

but not one month after. The effect size (SMD) of VAS reduction after two months of intradiscal PRP injections was -0.837 and that after six months of intradiscal PRP injections was -1.430 . The effect size (SMD) of ODI reduction at six months after PRP injections was -0.964 . Based on Cohen's d statistic, these effect sizes indicate that intradiscal PRP injections have large positive painreducing and functional improving effects in patients with discogenic lower back pain.

There are some proposed possible mechanisms behind the pain reducing and disc healing effect of intradiscal PRP injection. It has been reported that the platelet concentration of PRP is three to eight times of that found in whole blood; ${ }^{25,26}$ it has also been reported that PRP contains higher levels of cytokines and growth factors, which can stimulate the process of tissue repair and healing. ${ }^{25,26}$ Platelets secrete growth factors, such as insulin-like growth factor, EGF, TGF$\beta$, PDGF, VEGF, and basic fibroblast growth factor, which are needed for tissue healing and repair. ${ }^{15-18}$ These growth factors and cytokines may promote angiogenesis, accelerate endothelial regeneration, and increase collagen content in different types of tissues. ${ }^{15-18}$ In addition, they may stimulate quiescent stem cells to further promote the tissue healing and repair process. ${ }^{27}$

Theoretically, the regeneration and tissue healing process induced by intradiscal PRP injection may be more difficult than expected as the IVD is a complex and avascular structure relatively. However, in previous in vitro studies of human and animal disc cells, PRP demonstrated positive effects and growth factors released by PRP appeared to reduce apoptosis. ${ }^{19-21}$ Moreover, disc cells cultured with PRP exhibited improved annulus cell proliferation and proteoglycan synthesis. PRP has been reported to inhibit the inflammatory effect of interleukin-1 and TNF- $\alpha$ on cells of the nucleus pulposus. ${ }^{28}$ PRP also showed a beneficial effect on the experimentally injured discs of animals in in vivo studies. ${ }^{20-22}$ The results of these trials show the protective effect of PRP on degenerated IVDs of study subjects compared to those of controls; the effects include restoration of disc height and T2 signals on spine magnetic resonance images. ${ }^{22}$ Notably, there were no safety issues in these trials, nor were there any mutations of the nucleus pulposus cells that indicate an increased cancer risk. Due to its invasive nature, intradiscal PRP injection can theoretically cause adverse events such as disk neurologic injury, space infection, or progressive herniation; however, there was no report of any adverse event after intradiscal PRP injection the three studies ${ }^{1,2,4,23}$ included in the present meta-analysis. However, to thoroughly investigate the safety of intradiscal PRP injection, future studies with follow-up durations longer than six months are necessary.

In this study, we could not perform the analysis with data extracted from placebo or control group patients. Of the three included studies, only TuakliWosornu et $\mathrm{al}^{4}$ performed a study with a control group. The other two studies ${ }^{1,2}$ did not recruit placebo or control subjects. The recruitment of a placebo group is complicated with ethical issues because of the invasive nature of intradiscal injections. In addition, 


\section{A}

Study name

$\begin{array}{lccccccc} & \begin{array}{c}\text { Std diff } \\ \text { in means }\end{array} & \begin{array}{c}\text { Standard } \\ \text { error }\end{array} & \text { Variance } & \begin{array}{c}\text { Lower } \\ \text { limit }\end{array} & \begin{array}{c}\text { Upper } \\ \text { limit }\end{array} & \text { Z-Value } & \text { p-Value } \\ \text { Levi et al, 2016 } & -1.035 & 0.264 & 0.070 & -1.553 & -0.517 & -3.918 & 0.000 \\ \text { Tuakli-Wosornu et al, 2016 } & -0.335 & 0.191 & 0.036 & -0.709 & 0.039 & -1.755 & 0.079 \\ & -0.661 & 0.349 & 0.122 & -1.346 & 0.023 & -1.893 & 0.058\end{array}$
Statistics for each study

$-2.00$

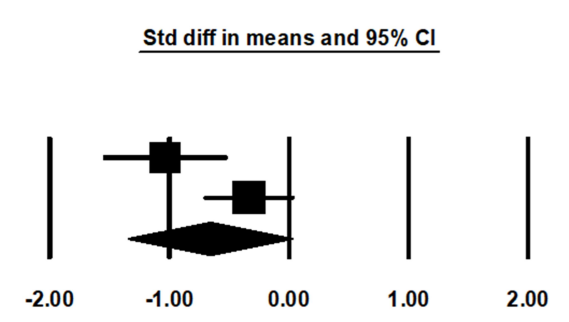

Favours A

Favours B

\section{B}

\begin{tabular}{lrrrrrrrr} 
Study name & \multicolumn{7}{c}{ Statistics for each study } \\
\cline { 5 - 8 } & $\begin{array}{c}\text { Std diff } \\
\text { in means }\end{array}$ & $\begin{array}{c}\text { Standard } \\
\text { error }\end{array}$ & Variance & $\begin{array}{c}\text { Lower } \\
\text { limit }\end{array}$ & $\begin{array}{c}\text { Upper } \\
\text { limit }\end{array}$ & Z-Value & p-Value \\
Levi et al, 2016 & -1.105 & 0.271 & 0.073 & -1.636 & -0.575 & -4.085 & 0.000 \\
Tuakli-Wosornu et al, 2016 & -0.681 & 0.206 & 0.042 & -1.085 & -0.277 & -3.305 & 0.001 \\
& -0.837 & 0.164 & 0.027 & -1.158 & -0.516 & -5.104 & 0.000
\end{tabular}

\begin{tabular}{|c|c|c|c|c|c|c|c|}
\hline \multirow[t]{2}{*}{ Study name } & \multicolumn{7}{|c|}{ Statistics for each study } \\
\hline & $\begin{array}{l}\text { Std diff } \\
\text { in means }\end{array}$ & $\begin{array}{l}\text { Standard } \\
\text { error }\end{array}$ & Variance & $\begin{array}{l}\text { Lower } \\
\text { limit }\end{array}$ & $\begin{array}{c}\text { Upper } \\
\text { limit }\end{array}$ & Z-Value & p-Value \\
\hline Levi et al, 2016 & -1.066 & 0.287 & 0.083 & -1.629 & -0.503 & -3.710 & 0.000 \\
\hline Jain et al, 2020 & -1.863 & 0.370 & 0.137 & -2.588 & -1.138 & -5.038 & 0.000 \\
\hline & -1.430 & 0.397 & 0.158 & -2.209 & -0.652 & -3.602 & 0.000 \\
\hline
\end{tabular}

Figure 2 Results of the meta-analysis of changes in visual analog scale scores one (A) two (B) and six (C) months after intradiscal platelet-rich plasma injection.

clinicians have limited options to control the discogenic lower back pain conservatively other than pain medications and physical therapy. Therefore, it would be difficult to find an appropriate procedure for the control group. However, despite these difficulties, the lack of placebo or control group is one of the limitations of the previous studies.

\section{Conclusion}

This study showed that intradiscal PRP injections are effective in relieving pain and improving disabilities caused by discogenic lower back pain. Notably, this pain- reducing effect significant manifests at two or six months after intradiscal PRP injections, but not one month after the injection. However, the present meta-analysis is limited in that we could not analyze data extracted from control or placebo groups. Of the three included studies included in this meta-analysis, only the RCT by TuakliWosornuet al. ${ }^{4}$ included a control group. The authors compared the effect of intradiscal PRP injection with that of a control injection treatment (contrast agent). Placebo or control subjects were not recruited in the other two studies. Also, for the evaluation of the effectiveness of intradiscal PRP, only two measurements (VAS and ODI) were used. 


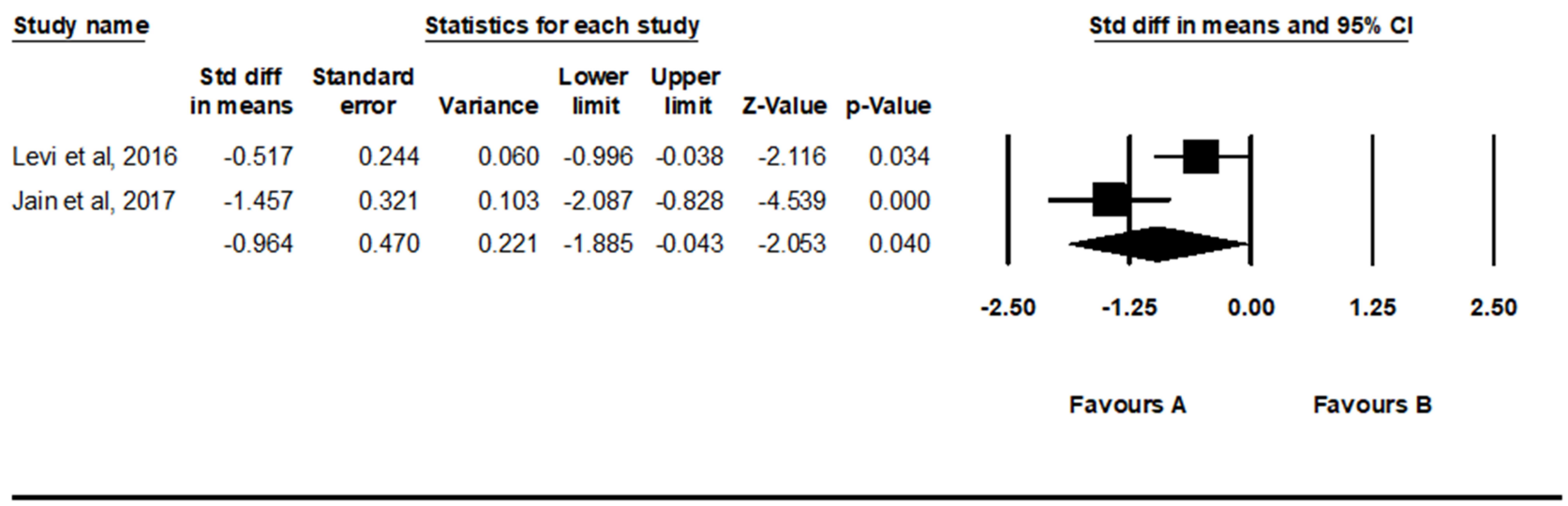

Figure 3 Results of the meta-analysis of changes in Oswestry Disability Index scores six months after intradiscal platelet-rich plasma injection.

\section{Abbreviations}

PRP, platelet-rich plasma; IVD, intervertebral disc; DDD, degenerative disc disease; VAS, visual analogue scale; VEGF, vascular endothelial growth factor; EGF, epidermal growth factor; TGF, transforming growth factor; PDGF, platelet-derived growth factor (PDGF); NOS, NewcastleOttawa scale; ODI, Oswestry Disability Index; RCT, randomized control trial; NRS, numeric rating scale; IGF, insulinlike growth factor; b-FGF, basic fibroblast growth factor.

\section{Ethical Publication Statement}

We confirm that we have read the Journal's position on issues involved in ethical publication and affirm that this report is consistent with those guidelines.

\section{Funding}

The present study was supported by a National Research Foundation of Korea grant funded by the Korean government (grant no. NRF-2019M3E5D1A02068106).

\section{Disclosure}

The authors report no conflicts of interest in this work.

\section{References}

1. Jain D, Goyal T, Verma N, Paswan AK, Dubey RK. Intradiscal platelet-rich plasma injection for discogenic low back pain and correlation with platelet concentration: a prospective clinical trial. Pain Med. 2020;21:2719-2725. doi:10.1093/pm/pnaa254

2. Levi D, Horn S, Tyszko S, et al. Intradiscal platelet-rich plasma injection for chronic discogenic low back pain: preliminary results from a prospective trial. Pain Med. 2016;17. doi:10.1093/pm/pnv053

3. Schwarzer AC, Aprill CN, Derby R, et al. The prevalence and clinical features of internal disc disruption in patients with chronic low back pain. Spine. 1995;20:1878-1883. doi:10.1097/00007632-19950900000007
4. Tuakli-Wosornu YA, Terry A, Boachie-Adjei K, et al. Lumbar Intradiskal Platelet-Rich Plasma (PRP) Injections: a Prospective, Double-Blind, Randomized Controlled Study. PM R. 2016;8:1-10. doi:10.1016/j.pmrj.2015.08.010

5. De Geer CM. Intervertebral disk nutrients and transport mechanisms in relation to disk degeneration: a narrative literature review. J Chiropr Med. 2018;17:97-105. doi:10.1016/j.jcm.2017.11.006

6. Burgstaller JM, Steurer J, Gravestock I, et al. Long-term Results After Surgical or Nonsurgical Treatment in Patients With Degenerative Lumbar Spinal Stenosis: a Prospective Multicenter Study. Spine. 2020;45(15):1030-1038. doi:10.1097/BRS.0000000000003457

7. Shi Y, Wang P, Hu X, Ye Z. Evaluation of the etoricoxib-mediated pain-relieving effect in patients undergoing lumbar fusion procedures for degenerative lumbar scoliosis: a prospective randomized, double-blind controlled study. Cell Biochem Biophys. 2015;71:1313-1318. doi:10.1007/s12013-014-0350-5

8. Park D. Ultrasound-guided s1 transforaminal epidural injection using the in-plane approach and color doppler imaging. Am J Phys Med Rehabil. 2018;97(3):e14-e16. doi:10.1097/PHM.0000000000000754

9. Jung YS, Suh JH, Kim HY, et al. The Prognostic Value of Enhanced-MRI and Fluoroscopic Factors for Predicting the Effects of Transforaminal Steroid Injections on Lumbosacral Radiating Pain. Ann Rehabil Med. 2016;40:1071. doi:10.5535/arm.2016.40.6.1071

10. Leggett LE, Soril LJ, Lorenzetti DL, et al. Radiofrequency ablation for chronic low back pain: a systematic review of randomized controlled trials. Pain Res Manag. 2014;19:e146-e153. doi:10.1155/ 2014/834369

11. Ito K, Creemers L. Mechanisms of intervertebral disk degeneration/ injury and pain: a review. Global Spine J. 2013;3:145-151. doi:10.1055/s-0033-1347300

12. Vilchez-Cavazos F, Millán-Alanís JM, Blázquez-Saldaña J, et al. Comparison of the Clinical effectiveness of single versus multiple injections of platelet-rich plasma in the treatment of knee osteoarthritis: a systematic review and meta-analysis. Orthop J Sports Med. 2019;7:232596711988711. doi:10.1177/2325967119887116

13. Piuzzi NS, et al. Platelet-Rich Plasma for the Treatment of Knee Osteoarthritis: a Review. $J$ Knee Surg. 2017;30:627-633. doi:10.1055/s-0037-1603795

14. Schneider A, Burr R, Garbis N, Salazar D. Platelet-rich plasma and the shoulder: clinical indications and outcomes. Curr Rev Musculoskelet Med. 2018;11:593-597. doi:10.1007/s12178-0189517-9

15. Foster TE, Puskas BL, Mandelbaum BR, Gerhardt MB, Rodeo SA. Platelet-rich plasma: from basic science to clinical applications. $\mathrm{Am}$ J Sports Med. 2009;37:2259-2272. doi:10.1177/0363546509349921 
16. Nguyen RT, Borg-Stein J, McInnis K. Applications of platelet-rich plasma in musculoskeletal and sports medicine: an evidence-based approach. PM R. 2011;3:226-250. doi:10.1016/j.pmrj.2010.11.007

17. Molloy T, Wang Y, Murrell G. The roles of growth factors in tendon and ligament healing. Sports Med. 2003;33:381-394. doi:10.2165/ 00007256-200333050-00004

18. Podd D. Platelet-rich plasma therapy: origins and applications investigated. JAAPA. 2012;25:44-49. doi:10.1097/01720610201206000-00009

19. Chen WH, Lo W-C, Lee -J-J, et al. Tissue-engineered intervertebral disc and chondrogenesis using human nucleus pulposus regulated through TGF-betal in platelet-rich plasma. $J$ Cell Physiol. 2006;209:744-754. doi:10.1002/jcp.20765

20. Gullung GB, et al. Platelet-rich plasma effects on degenerative disc disease: analysis of histology and imaging in an animal model. Evid Based Spine Care J. 2011;2:13-18. doi:10.1055/s-0031-1274752

21. Obata S, Akeda K, Imanishi T, et al. Effect of autologous platelet-rich plasma-releasate on intervertebral disc degeneration in the rabbit anular puncture model: a preclinical study. Arthritis Res Ther. 2012;14:R241. doi:10.1186/ar4084

22. Li P, Zhang R, Zhou Q. Efficacy of platelet-rich plasma in retarding intervertebral disc degeneration: a meta-analysis of animal studies. Biomed Res Int. 2017;2017:7919201. doi:10.1155/2017/7919201
23. Higgins JP, Altman DG, Gotzsche PC, et al. The Cochrane Collaboration's tool for assessing risk of bias in randomised trials. BMJ. 2011;343:d5928-d5928. doi:10.1136/bmj.d5928

24. Stang A. Critical evaluation of the Newcastle-Ottawa scale for the assessment of the quality of nonrandomized studies in meta-analyses. Eur J Epidemiol. 2010;25:603-605. doi:10.1007/s10654-010-9491-z

25. Dhurat R, Sukesh M. Principles and methods of preparation of platelet-rich plasma: a review and author's perspective. J Cutan Aesthet Surg. 2014;7:189. doi:10.4103/0974-2077.150734

26. Cole BJ, Seroyer ST, Filardo G, Bajaj S, Fortier LA. Platelet-rich plasma: where are we now and where are we going? Sports Health. 2010;2(3):203-210. doi:10.1177/1941738110366385

27. Chellini F, Tani A, Zecchi-Orlandini S, Sassoli C. Influence of platelet-rich and platelet-poor plasma on endogenous mechanisms of skeletal muscle repair/regeneration. Int J Mol Sci. 2019;20 (3):683. doi:10.3390/ijms20030683

28. Kim HJ, Yeom JS, Koh Y-G, et al. Anti-inflammatory effect of platelet-rich plasma on nucleus pulposus cells with response of TNF-alpha and IL-1. J Orthop Res. 2014;32:551-556. doi:10.1002/ jor. 22532

\section{Publish your work in this journal}

The Journal of Pain Research is an international, peer reviewed, open access, online journal that welcomes laboratory and clinical findings in the fields of pain research and the prevention and management of pain. Original research, reviews, symposium reports, hypothesis formation and commentaries are all considered for publication. The manuscript management system is completely online and includes a very quick and fair peer-review system, which is all easy to use. Visit http:// www.dovepress.com/testimonials.php to read real quotes from published authors. 